\title{
The Authenticity of Social Media Information among Youth: Indian perspective
}

\author{
Dr. Vinod Bhatt'1,Ms. Khushboo Goyal ${ }^{2}$ and Dr. Anita Yadav ${ }^{3}$
}

\begin{abstract}
We are living in a world where media landscape is changing rapidly. India is a young country with lots of opportunities and possibilities to flourish and enjoy the world wide information. The youth, particularly, in India is growing up within a world of inescapable technology as the first generation learners. The medium of exchanging the information has changed; now the information exchange takes place through Facebook, Twitter, Emails, YouTube, WhatsApp and so on, to communicate and disseminate information and knowledge with others. A very alarming fact is that the youths are barring newspapers, books and magazines and consider social media as the best platform to find latest happenings, trends and new information. However, the liability and the authenticity of social media messages among youth is always under question marked. The purpose of this paper is to explore whether and to what extent social media information is reliable and authentic. More importantly, what kind of content gives the most value to the youth? The paper will also classify the different content spread through social media and its impact over society especially youth. The research will be evaluated on the random sampling covering size 150 (population), targeted audience will be youth from different states of India. The objective of this paper is to attain statistics from youth to check the reliability and validity of the social media content.
\end{abstract}

Key words: Social Media and Youth, Reliability and Dependency on the Social Media Content

\section{Introduction}

Our society has become tech savvy where everyone relates to a single touch of our smart phones. The major connecting tools that we all have is social media, be it Twitter, Facebook, YouTube, WhatsApp, Instagram, and so on. Over the past 15 years, the world has been taken by storm through the onset of social media. According to a report it has known that around $90 \%$ people who uses internet, visit the social media. Because we live in such a largely global society, creating and maintaining an outline presence has become most relevant in promoting your brand and expanding your social network. We are living in a digital knowledge world where most of the information comes through the channel social media. Social media acts as a positive implication for many people living in developing countries and some of the largest social media companies are at the heart of these positive changes. Social media gives a voice to people to express what they believe and what they follow. Social media has become the prominent part of the life of the youth. . However, the liability and the authenticity of social media messages among youth is always under question marked. Therefore, it is essential to explore whether and to what extent social media information is reliable and authentic. Undoubtedly, authenticity and transparency are

\footnotetext{
${ }^{1}$ Associate Professor,

2Student

${ }^{3}$ Sr. Assistant Professor, VIT University Bhopal
}

often used interchangeably despite the concepts' fundamental differences. Authenticity is related to image consistency and perceived genuineness, while being forthcoming with all information that can affect the relevant stakeholder of the firm. Social media seems to be the heartbeat of todays' culture.

\section{Objective of the Study}

The main objective of the study to analyse the credibility of new media among the youth

- To find out the reliability of social media content among youth particularly in India

- To find out compatibility between new media and its frequent users i.e. youth, who are considered as sensitive generations.

\section{Research Hypothesis}

The hypothesis was raised to this significant study-

"Evaluation of content/s on Social Media among Youth"

\section{Literature Review-}

The credibility and authenticity of social media content is a topic for debate. Some author proposes that "online information is higher credibility than information from any other more traditional media". On the other hand, other argued that online information can be "posted by an individual and thereafter is less credible than other types of information sources". Ismail 
,Shahrinaz\&LatifRoslina Abdul (2013) critically examined the topic "Regardless of the diverse researches conducted on social media, these are very limited number of studies that especially examine how people develop their perception of information credibility towards information posted to online reviews sites and consequences". Social media and its "Authenticity is the key component of what makes social media so successful for businesses. Authentic social media is the modern day testimonial: It allows users to interact with businesses in real time, but also creates an open space for conversation and feedback. If a person is having a hard time receiving assistance from a business's customer service, for instance, all they need to do is tweet at them for a response. Other users can get involved depending on the severity of the situation, forcing all sides to be accountable." (Kelly Samuel 2017). On the other hand, D. Gefen having a different opinion on the topic. He elucidates, "The Internet is an environment full of uncertainty and various types of players, and an online user always experiences some level of risk. Thus, trust has become the strategy for dealing with uncertain outcomes or future and it is considered one of the most reliable predictor for online behaviours." According to (Kesha Coker, Katharine Howie, HollySyrdal 2017) "There is a broad consensus among practitioners and academicians that the success of social media communication relies heavily on the perceived authenticity of the content. Also, transparency - not to be confused with authenticity - has received significant attention in both the literature and the mainstream media in recent months".

\section{Methodology}

The study is based on primary as well as secondary data. The primary data is collected through survey method which includes a questionnaire using self-made close and open ended of 14 questions was prepared and duly filled by the 150 students of different states of India studying in VIT Bhopal University. The highest priority is given to the primary data which provides the first hand information on the topic. A descriptive research design (quantitative research) model is used to achieve the objective of the research topic. The data collection is based on cross sectional design. The research includes huge amount of literature review where every minute aspects of the topic scrutinized critically. In the process of literature review, we identified the different related variables and the same were crosschecked and re-verified by the experts. Once we come up with a variable, the questionnaire has been prepared. Cronbach's alpha is applied on data to check the reliability. On the basis of results of this study, conclusion and suggestion are done.

\section{Sampling}

To study this topic, random sampling method is applied. In the random sampling technique, each member of the population has an equal chance of being selected as subject. The entire process of sampling is done in a single step with each subject selected independently of the other members of the population.

\section{University of the Study}

As per the set parameters, VIT Bhopal university had chosen to achieve the objective of the research.

\section{Data Analysis}

1. What do people mainly look for in social media?

In the above question, majority of people think that the major use of social media involves recreation and entertainment, Instagram and Facebook being the most significantly used modes for following trends and becoming the definition for fun for the youth, taking up a great amount of time from their schedule.

2. Should social media be checked before it spreads a message?

The messages that once become viral over social media are difficult to stop. Many such messages include disturbing images, videos and confidential information that is way too sensitive to be public knowledge and hence the survey shows that almost $94 \%$ people are in favour of censor boards to check the posts before they were made public.

3. Will the society grow without social media now?

Technology is growing in a fast pace. Students study over their laptops using google, YouTube and other study apps on their phones; people become famous over social media and turn their fame as their livelihood, parents let their childhood play video games, using Instagrametc to divert their mind and what not.

4. Does social media influence or affect our judgement in a negative way towards a person an object?

The survey shows that sometimes our judgements become clouded and biased based on comments we read about a person on twitter or Facebook and inclines us towards a negative thought towards them. 
Objects or products if not shown with a good rating, automatically make us think ill of it without even giving it a try. Hence our perspectives become varied with others.

5. What is the most important work for any social media?

Advertisements are majorly done by social media. Among all others aspects like news headlines, jobs and placements, research etc. The industry that makes the most out of social media is the advertisement. Prints, posters and several other ways of advertising a product, all lose pace and social media is the fastest mode of the same.

6. Is social media effective enough for assessing knowledge?

Social media provides the students with enormous number of ways of assessing knowledge and gaining benefits. People who can't afford books and notes can easily download a pdf and study. Teachers also rely on YouTube videos and explanatory sessions for their students and hence our survey shows that people do rely on social media for assessing knowledge.

7. Is the knowledge assessed through social media reliable enough?

There's always at least one loop hole in every good thing that proves to be beneficial but we use it anyway because it helps us. So, saying that social media is reliable doesn't hurt bad anyone who uses it should cross check, just to be sure of what they are using.

8. Which site is the most reliable source of information?

Any blog made is a personal opinion or a write up about something that a person really believes in. so, any dedicated write up can be considered reliable. As far as Facebook and twitter go, the comments would be given the benefit of doubt. But yes, among all other apps, these prove to be the most frequently used and trusted.

9. What kind of common messages does social media spread?

Social media being the trend that everyone follows is responsible for the fashion change among the youth. starting from footwear to the most fashionable accessories, social media exaggerates it all, making it all making it a,'new trend' that makes you look cool. Also, keeps up different opportunities and fresh changes for the people to look forward.
10. How often do you find unwanted /abusive/useless/slang contents on social media?

People sometimes find unwanted or random stuff and posts on social media that makes no sense and is almost useless to them or of no interest to them. They often pick up slang language too, that disrupts their speaking skills but is still the most commonly used recreational technology for the youth.

11. Does social media promote a healthy mindset for the youth?

Children tend to learn a lot from what they visually perceive. Whatever they see daily, influences their way of thinking and moulds their point of perception in the growing age of the teen, their minds will be reflection of everything they have been taught at one point or the other.

12. Does the use of social media make us antisocial?

While sitting with people in a group, instead of talking to each other, they use their phones and prefer to chat over social medias rather than talking in person. The survey shows that social media up to some extent is making the youth anti-social and pulling them towards a technological phase.

13. Does social media occupy your mind all day with "food for thought"?

Do we keep thinking about one thing or the other? Yes, its human tendency to keep the brain running analysing one thought after the other. Social media makes this work easier for us. We tend to think more as we see more. We see varied over social media and occupy our mind for long creating voids for more.

14. Is your life style disturbed or compromised because of social media?

The survey shows that $98.5 \%$ of the youth has a disturbed lifestyle due to availability of social media at all hours. They tend to disrupt their sleeping schedule, studying hour's outdoor time, eating habits

And stuff because of overuse of phones, TVs \& laptops. Such habits indeed are disturbing for our generation and would be a major disturbance in the time to come.

\section{Findings and conclusions}

Social media has significantly proven itself as the biggest asset to the human kind. Technology would never have developed so much had it not 
been for social media. How? Our survey shows that maximum no. Of people tend to infer about the latest trends and technological advancements because of social media and its advertisements. It promotes the development in every field irrespective of its genre. Be it fashion,science,reading,technology or food and delicacies. All the aspects starting from environmental issues to their precautions and cure are showed upon the social media.

Coming to the authenticity, the teenage population believes that the information they get is mostly authentic. There are always pros and cons to a subject, but it showed that students, teachers and parents all rely upon the social media for help and research. It's the finest way of helping as it can afford to provide knowledge to the poor,who cannot afford books and entertainment to the rich who would do anything to maintain their pace with the changing trends. Affecting and inclining our thoughts on a subject, social media helps us understand the difference between the good and the best version of a product.

The survey also shows that as much as it promotes a healthy mindset for the growing buds, it should be kept on check as it can make them anti-social if availed to them at all hours.

Everything can be a blessing to the society if used properly and the exploitation of any good thing can prove to be devastating. So it is safe to conclude that social media is an important aspect which is authentic and helpful for its users as well as for the development and growth of the society.

\section{References}

Gupta, N. (1998) Switching Channels-ideologies of Television in India. New Delhi: Oxford University Press.

Bagdikian, Ben H. (1997). The Media Monopoly Fifth Edition. Boston: Beacon Press.

Venkataramiah, E. S. (1987). Freedom of Press: Some recent trends. Delhi: B. R. Publishing House.
ChughPinki.(2014). 'Impact of Media and Social Networking on English Languages'. The Impact of Social Changes on English language and literature. New Delhi.

Jacobsen, W. C., \&Forste, R. (2011). The Wired Generation: Academic and Social Outcomes of Electronic Media Use among University Students.

Buckingham, D (2002). The Electronic Generation?Children and New Media. Manchester: Manchester University Press.

GhulamShabir, Y. M. (2014, November). The Impact of Social Media on Youth: A Case Study of Bahawalpur City. Asian Journal of Social Science and Humanities, 3 (4), 132-151. Retrieved March 02, 2016, From http://www.ajssh.leenaluna.co.jp/AJSSHPD Fs/VOL.3(4)/AJSSH2014(3.4-13).pdf

Minal D. (2014).Reflections on New Media.In N. Khattari (ed.), Interactive Media and Society (p.129). Delhi: Kalpaz Publications.

Ismail,Shahrinaz\&LatifRoslina Abdul. (2013). Authenticity Issues of Social Media: Credibility, Quality and Reality. World Academy of Science, Engineering and Technology International Journal of Humanities and Social Sciences.https://waset.org/publications/342 6

D. Gefen, "E-Commerce: The role of familiarity and trust," Omega-Int J Manage Sci, vol. 28, 2000, pp. 725-737.

Kesha Coker, Katharine Howie, Holly Syrdal. (2017). Back to the Future: Using Marketing Basics to Provide Customer Value Proceedings of the 2017 Academy of Marketing Science (AMS) Annual Conference Editors "The Truth About Transparency and Authenticity on Social Media: How Brands Communicate and How Customers Respond" pp 659-660. 